\title{
EPIMELEIA HEAUTOU: FILOSOFÍA APLICADA CON ALGUNAS RECOMENDACIONES PLATÓNICAS
}

\section{EPIMELEIA HEAUTOU: APPLIED PHILOSOPHY WITH SOME PLATONIC RECOMMENDATIONS}

\author{
Enrique de Jesús Aguilar Prado \\ Universidad Franciscana de México \\ dialectikos@gmail.com
}

RECIBIDO: 23 DE MARZO DE 2012

ACEPTADO: 20 DE JULIO DE 2012

\begin{abstract}
Resumen: Si los filósofos delimitan el rendimiento teórico de los conceptos o explicitan los supuestos metafísicos y epistemológicos de una proposición, ¿cómo pueden establecerse líneas generales que guíen al hombre a vivir mejor a través de la Filosofía Aplicada? Platón propone el camino de la ignorancia: una vez que el individuo sea consciente de su posición frente a lo que sabe, entonces podrá disponerse a vivir bien, porque a través del discernimiento el hombre puede alcanzar la felicidad. Hacer perpleja a una persona es sólo el primer paso para que por sí misma reconozca qué esperar, qué debería evitar y cuál es la mejor elección que puede tomar de acuerdo a su realidad.

Palabras clave: Platón, problematización, discernimiento, felicidad.
\end{abstract}

\begin{abstract}
If philosophers define theoretical performance of concepts or they state assumed metaphysical and epistemological aspects of a proposition, how can they establish a general approach that guides man to live better through Applied Philosophy? Plato proposes ignorance path: when subject is aware of what they know, it can set out to live well. It is through discerning acts that man can achieve happiness. To provoke perplexity on someone is the first step to recognize what he has to wait for, what he has to avoid, and what is the best choice to make according to his reality.

Key words: Plato, problematization, discernment, happiness.
\end{abstract}

\section{Un breve acercamiento al problema}

La dialéctica puede concretarse a través de la vía política o social en términos hegelianos o marxistas; sin embargo, este artículo se centra en exponer los fundamentos teóricos y las recomendaciones prácticas para ejercer consejería filosófica a partir de los planteamientos platónicos. Hunde sus reflexiones en el paradigma griego por iniciar allí el cuidado de sí (epimeleia heautou), una aplicación de la filosofía que se inserta en la vida de los ciudadanos.

Pudo consultarse para este trabajo el famoso Alcibiades I en el que Platón expone las referencias del cuidado de sí, sin embargo ya ha sido estudiado por 
grandes personajes como Michel Foucault ${ }^{1}$ o Giovanni Reale ${ }^{2}$; además, supone un peligro en términos de un sustento sólido en tanto que su autenticidad aún no se acepta por completo en la comunidad filosófica. En cambio, he decidido retomar las referencias de los diálogos que son aceptados por casi todos los estudiosos de Platón, como la República, el Fedro, el Menón, el Protágoras, el Fedón y el Timeo, entre los más importantes, para demostrar la validez de los planteamientos del cuidado del alma y el cuerpo, así como ofrecer un tejido conceptual que es útil tanto para académicos como para aquellos que ejercen la Filosofía Aplicada. Entiendo que se usa los diálogos o mini-diálogos socráticos como una técnica para los cafés filosóficos; aun así, desconozco si los términos expuestos aquí pueden tener un rendimiento mayor al de la consejería, esto es, si pueden implementarse en otras áreas de la Filosofía Aplicada.

Para lograr el objetivo propuesto, el artículo está dividido en cuatro partes. Las primeras tres hacen un detenimiento más teórico (sin olvidar por ello su conexión con la práctica filosófica) de los conceptos problematización (aporein), alma (psique) y discernimiento (phronesis), en ese orden. El último hace referencia a reflexiones sobre la aplicación de estos conceptos a la consejería. Al final hay una pequeña bibliografía sobre las obras consultadas en este trabajo.

\section{Sobre el concepto de aporein}

Aporein es una palabra griega, cuya traducción más exacta es problematizar. Tiene el significado de investigación, en el entendido que de fondo hay una inconmensurabilidad $^{3}$. Cada vez que accedemos a la realidad y la comprendemos paulatinamente se manifiesta esta inconmensurabilidad, en consecuencia, permite que la filosofía no se dogmatice, que delimite los conceptos que los filósofos tratan.

Platón habla con mayor detenimiento sobre aporein en el diálogo Menón. El contexto de ese diálogo es la indagación de si la virtud es enseñable o no. Para demostrar que conocer es recordar, Sócrates hace un experimento: llevar a un esclavo a reconocer el cálculo de una superficie, sin enseñarle. Sócrates

\footnotetext{
${ }^{1}$ Cfr. FOUCAULT, M.: Historia de la sexualidad. Tomo II: El uso de los placeres, Editorial Siglo Veintiuno, México, 1998; FOUCAULT, Michel: Tecnologías del yo y otros textos afines. Editorial Paidós, Barcelona, 1900.

2 Cfr. REALE, G.: Raíces culturales y espirituales de Europa: por un renacimiento del hombre europeo. Editorial Herder, Barcelona, 2005.

${ }^{3}$ Cfr. SCOTT, D.: Plato's Meno, Cambridge University Press, Cambridge, 2005, p. 33.
} 
guía al esclavo mediante preguntas a ser consciente que, aunque cree que conoce el cálculo correcto, está equivocado. Con esa referencia Platón habla sobre el problematizar.

Problematizar no significa que la filosofía se invente problemas, sino que manifieste los existentes. Las palabras de Sócrates son reveladoras entendido así el concepto: "no es que teniendo yo problemas, problematice sin embargo a los demás, sino que estando yo totalmente problematizado también hago que lo estén los demás"4.

Así pues, la filosofía no tiene por cometido inicial fundar fantasmas o entidades nuevas, inexistentes; sino que la filosofía, en general, tiene el papel de abrir el concepto, de sacar las consecuencias de los argumentos y de poner de manifiesto las falacias y las inconsecuencias. Esta característica reincide en la consejería filosófica, que en términos socrático-platónicos, tiene su cumplimiento en el diálogo. Éste es el medio para que tanto el filósofo como el interlocutor puedan participar de los argumentos y descubrir qué inconsistencias hay en un discurso dado.

Problematizar es hacer patentes los problemas, no crearlos; aunque el resultado sea estar lleno de dificultades. De hecho, es el personaje de Sócrates el que reconoce que está lleno de problemas, pero que al preguntarle a los demás, no los aletarga como el pez torpedo para provocarles un mal, haciendo que piense y examine con detenimiento lo que está diciendo; sino que los hace llegar al mismo nivel de perplejidad.

De tal manera que el fundamento de la actividad comunitaria del filósofo para enredar y provocar a los interlocutores una posición negativa frente a la respuesta es la perplejidad del pensamiento del filósofo mismo; perplejidad que comunica, actividad en la que incluye a sus conciudadanos y colegas (como lo hizo Sócrates en su vida en la polis).

El filósofo, para Platón, tiene la función de demostrar que vivimos en la ignorancia, y para ello se basa en llevar los argumentos del otro al absurdo. Mientras los filósofos están perplejos ante los problemas deben demostrar la inconmensurabilidad de los planteamientos, llevarlos hasta la aporía, donde obtienen su función teorética y su rendimiento práctico.

El personaje Sócrates devela que el resultado de problematizar no es liberar a una persona de la ignorancia, pero sí ponerlo en una mejor posición, a saber, que la reconozca:

\footnotetext{
${ }^{4}$ PLATÓn: Diálogos. Tomo II: Gorgias, Menéxeno, Eutidemo, Menón y Crátilo, Editorial Gredos, Madrid, 1983, p. 300
} 
¿Entonces está ahora en una mejor situación con respecto del asunto que no sabía? -Así parece. -Al problematizarlo y entorpecerlo, como hace el pez torpedo, ¿le hicimos algún daño? -A mí me parece que no. -Le hemos hecho, al contrario, un beneficio para resolver cómo es la cuestión ${ }^{5}$

¿Cuál es el beneficio del cual habla Sócrates? ¿Qué ventaja tiene una persona que está perpleja y problematizada con respecto a la que no lo está? Una vez que el otro reconoce su ignorancia es más sencillo ponerse a investigar conjuntamente algo que se quiere definir. Pues, cuando reconocemos nuestra ignorancia sentimos el deseo de obtener lo faltante, como lo expresa en el Banquete: "cualquiera... que sienta deseo, desea lo que no tiene a su disposición y no está presente, lo que no posee, lo que él no es y de lo que está falto" 6 , porque ¿quién buscaría lo que ya cree tener? Ante esto, aporein se consolida un beneficio en tanto que libera al alma de su ignorancia.

Para Platón, aporein no se configura como un inflacionismo conceptual; no es un llenarse de problemas a uno mismo y a los demás. Problematizar es la posición original de una investigación porque equivale a la toma de consciencia de la propia ignorancia, y se establece como una disposición que prepara para llegar a la verdad. Así las palabras del personaje Sócrates:

Y ahora, <qué es la virtud>, tampoco lo sé; pero tú, en cambio, tal vez sí lo sabías antes de ponerte en contacto conmigo, aunque en este momento asemejes a quien no lo sabe. No obstante, quiero investigar contigo e indagar qué es ella ${ }^{7}$

Para el ateniense, problematizar ya es en sí mismo un bien que produce la filosofía. Ella cura la ignorancia al ser consciente de ella porque permite estar dispuesto a conocer los fundamentos de la realidad. O como se expresa en la República ${ }^{8}$ : aunque el prisionero de la caverna no conozca esa primera liberación a la que se somete, al conocer las Ideas, reconoce en primer lugar que las sombras que veía no eran los verdaderos objetos. Sólo cuando se dé esta liberación el humano será capaz de realizar el bien en la realidad, obteniendo su verdadera libertad ${ }^{9}$. Así, aporein se constituye una ventaja de la filosofía platónica por permitir mejorar las condiciones epistémicas.

\footnotetext{
${ }^{5}$ PLATÓn: Diálogos. Tomo II: Gorgias, Menéxeno, Eutidemo, Menón y Crátilo, Editorial Gredos, Madrid, 1983, p. 299.

${ }^{6}$ PLATÓN: Diálogos. Tomo III: Fedón, Banquete y Fedro, Editorial Gredos, Madrid, 1986, p. 242.

${ }^{7}$ PLATÓn: Diálogos. Tomo II: Gorgias, Menéxeno, Eutidemo, Menón y Crátilo, Editorial Gredos, Madrid, 1983, p. 300.

${ }^{8}$ Cfr. PLATÓN: Diálogos. Tomo IV: República, Editorial Gredos, Madrid, 1986, p. 354.

${ }^{9}$ Cfr. VELÁSQUEZ, O.: "La República de Platón: Línea, Caverna, Dialéctica", disponible on-line
} 
Con lo dicho anteriormente, podemos sintetizar la posición de Platón con respecto al beneficio de aporein con la siguiente cita refiriéndose a un problema matemático que Sócrates le ha puesto al esclavo de Menón:

Le hemos hecho... un beneficio para resolver cómo es la cuestión. Ahora, en efecto, buscará de buen grado, puesto que no sabe, mientras que muchas veces antes, delante de todos, con tranquilidad, creía estar en lo cierto.... ¿Crees acaso que él hubiera tratado de buscar y aprender esto que creía que sabía, pero ignoraba, antes de verse problematizado y convencido de no saber, y de sentir el deseo de saber? -Me parece que no, Sócrates. $-i \mathrm{Ha}$ ganado, entonces, el verse entorpecido? - Me parece ${ }^{10}$.

\section{Sobre el concepto de psique}

Aporein se consolida un beneficio en tanto que libera al alma de su ignorancia. Pero, ¿qué tipo de entidad entendemos cuando hablamos de alma? Comprendemos el alma como una substancia que le da funciones específicas al viviente. Alma humana se relaciona con el sujeto, con un "yo" cognoscente ${ }^{11}$. Para Platón, la noción del alma de los vivientes se deriva de la del cosmos. En el Timeo expresa que el alma del mundo fue tomando una forma racional, porque al tener el mundo una forma esférica esta expresa una relación perfecta y armónica entre sus partes. El alma del mundo es lo que le da movilidad a lo existente; y una vez que se entrelazó con la materia desde el centro hasta sus extremos y compenetró en ella circularmente, debido a su forma esférica, "se puso a girar sobre sí misma y comenzó el gobierno divino de una vida inextinguible e inteligente que durará eternamente" ${ }^{12}$.

Si seguimos este primer momento del alma, entonces se caracteriza por ser incorpórea e inmortal. Que ejecuta movimientos circulares, los más perfectos entre la geometría por ser el círculo la única figura cuyos puntos de la circunferencia siempre están a la misma distancia. Por tal razón afirma Platón que es la mejor de las composiciones: "Mientras el cuerpo del universo nació visible, ella [el alma] fue generada invisible, participe del razonamiento y la

en: http://www.diadokhe.cl/media/platonica/republica_polit.pdf (último acceso 19 de abril de 2011).

${ }^{10}$ PLATÓN: Diálogos. Tomo II: Gorgias, Menéxeno, Eutidemo, Menón y Crátilo, Editorial Gredos, Madrid, 1983, pp. 308-309.

${ }^{11}$ Cfr. REALE, G.: Raíces culturales y espirituales de Europa: por un renacimiento del hombre europeo. Editorial Herder, Barcelona, 2005, p. 82.

${ }^{12}$ PLATÓN: Diálogos. Tomo VI: Filebo, Timeo y Critias, Editorial Gredos, Madrid, 1992, pp. 180181. 
armonía, creada la mejor de las criaturas por el mejor de los seres inteligibles y eternos" $"$.

Pero, ¿cuál es el papel del alma del mundo dentro de la relación epistémicoontológica, pues de ello deriva que aporein cumpla su labor de liberarnos de la ignorancia? Puesto que problematizar no es un sustantivo, sino una acción; aporein no puede estar presente en abstracto. Siempre se problematiza bajo una instancia concreta, el yo (psique). Este es al mismo tiempo el objeto propio que se problematiza (se problematizan sujetos particulares); y la instancia concreta a través de la que se concretiza aporein, esto es, que un sujeto se problematice a sí mismo. ¿Pero cómo sucede esto? En términos llanos psique es el sujeto y el objeto de la actividad de problematizar ${ }^{14}$.

El alma del cosmos, al ser racional ${ }^{15}$, está en contacto con los objetos. Los conoce a través de la circularidad de la que participa, de la que la ha dotado el demiurgo. Cuando en esos giros se encuentra con un objeto cuya esencia es divisible $^{16}$ puede expresar a qué es idéntico, a qué es diferente y a qué es relativo; estableciendo cómo y cuándo es relativo o afectado por otro objeto que deviene o por un ente inmutable y eterno.

El alma del mundo tiene esta capacidad de establecer la identidad y la diferencia porque participa de los tres movimientos del cosmos, a saber, el de la naturaleza de lo mismo, de lo diferente y del ser. Al participar de ellos tiene la disposición de expresar a qué es idéntico, a qué es relativo y a qué es diferente, como mencionamos arriba.

Cuando en su movimiento dice cada uno de estos atributos, pueden ocurrir dos cosas: o bien, manifestar que su esencia divisible pertenece al ámbito de la sensibilidad, en cuyo caso, surge la doxa y sus objetos son de menor estatus ontoepistémico. Las opiniones son tan mutables como los objetos del cosmos, y por lo tanto, no son susceptibles de fundar la experiencia científica (episteme).

Cuando el alma del mundo se encuentra con entidades de tipo inteligible, entonces el pensamiento puede gestar verdadera y real episteme o conocimiento noético. Este se construye mediante conceptos en un despliegue dialéctico, según Platón. Este tipo de conocimiento que genera el alma es confiable porque es la negatividad la que delimita y confirma el concepto al establecer con un parámetro de evidencia epistemológica ${ }^{17}$, en la medida en que responde a un

\footnotetext{
${ }^{13}$ PLATÓN: Diálogos. Tomo VI: Filebo, Timeo y Critias, Editorial Gredos, Madrid, 1992, p. 181.

${ }^{14}$ Esta es la razón por la que el terapeuta platónico en la consultoría no puede darle las respuestas al sujeto, sino aducirlas a través de preguntas a semejanza del trabajo de parto socrático.

${ }^{15}$ Porque lo racional es el orden más perfecto que existe, según los griegos.

${ }^{16}$ Un objeto, sea una divinidad, una idea o una cosa del mundo material; cuya referencia sea distinta del demiurgo.

${ }^{17}$ Muy semejante a la regla cartesiana de no aceptar como verdadera cualquier idea que no sea clara
} 
objeto que no es mutable y cuyo conocimiento esencial es más puro, puesto que es inteligible y no corpóreo.

Pero, ¿qué hay del alma de los seres vivientes particulares? Ya que del alma del cosmos se deriva la nuestra, Platón no duda en reiterar que ella también es lo mejor que tenemos ${ }^{18}$. El alma individual, dice, está completamente enlazada con el ámbito moral y la referencia epistémico-ontológica. No necesariamente son excluyentes, sino que una reclama a la otra incluyéndola. Sólo en el aspecto metodológico, comencemos por la parte moral, describiéndola como si no se enlazara con lo epistémico, después regresaremos a ello.

El alma humana es afectada principalmente por varios procesos: una percepción cuando existe la entrada o salida de elementos en el cuerpo, dando como resultado cambios violentos; y en segundo lugar sentimientos como amor, que se mezclan con placer y dolor ${ }^{19}$; el temor y la ira. Sea lo que se oponga por naturaleza con el cuerpo o el alma.

$\mathrm{Si}$ estas realidades corpóreo-psíquicas (placer, dolor, temor, ira) son dominadas, entonces habremos de vivir con justicia; pero si ocurre lo contrario, en injusticia. Porque para Platón el que viva correctamente durante el tiempo que le sea asignado a este mundo sensible podrá regresar al origen, y tendrá una vida feliz. Pero si falla, entonces tendrá por castigo volver a intentarlo, pero esta vez bajo la forma femenina de la especie humana. Y si aun así fallara, entonces se transformará en un animal que asemeje el vicio que lo ha corrompido ${ }^{20}$. No nos adentraremos en el pasaje de Fedro donde explicita en qué tipo de animales se convierte el humano en razón de su vicio porque ello implicaría desarrollar un apartado sobre la transmigración y abriría un campo de posibilidades muy extenso para investigar.

Al mencionar que hay varios procesos que afectan al humano, sea dolor, placer, ira o temor, va surgiendo la función moral, a saber, que o se deja dominar por los ruidos y lo irracional o la psique los domina mediante los razonamientos accediendo a la primera y mejor actitud moral, es decir, siendo virtuosos. Pero, ¿cómo es que el hombre puede acceder a la virtud? Pues bien, hemos dicho que el alma individual se deriva del alma del cosmos. Esto está bien dicho, sin embargo, cabe aclarar que en el Timeo y en la República Platón distingue tres

\footnotetext{
ni distinta.

${ }^{18}$ Cfr. PLATÓN: Diálogos. Tomo VIII: Leyes, Editorial Gredos, Madrid, 1999, p. 394.

${ }^{19}$ Platón se refiere aquí a que cuando grandes partículas se descargan de nuestro cuerpo, vaciándose lentamente en contra del orden natural, y después se carga en grandes cantidades y de manera acelerada, entonces obtenemos placer; pero que si se descarga rápido y se carga lentamente entonces produce dolor como en las cortaduras o quemaduras, en el caso del cuerpo.

${ }^{20}$ Cfr. PLATÓN: Diálogos. Tomo VI: Filebo, Timeo y Critias, Editorial Gredos, Madrid, 1992, pp. 189-190.
} 
partes del alma humana. Una con la que razonamos, que designamos con el mismo signo (racional); otra que siente hambre y sed, y a su vez desea todos los demás apetitos, concupiscible; y finalmente aquella con la que nos enojamos, la irascible.

Cada una de estas, dice Platón, da lugar al tipo de habitantes dentro de la organización social de la polis: el Filósofo, puesto que se ejercita en la dialéctica debe ser el gobernante, ya que él es portador del discernimiento y la previsión al tener el alma racional más desarrollada que los otros ciudadanos. La virtud con el que caracteriza a estos personajes en la República es la sabiduría.

Los guerreros son aquellos que tienen más desarrollada el alma irascible. Ellos deben ser los auxiliares de los filósofos en el proyecto político de Platón, siempre que no se pervierta esta parte del alma por una mala educación. Los guerreros son los encargados de salvar el estado ante los enemigos. Para lograr su objetivo requieren de la virtud de la valentía, que consiste en que lo irascible mantenga el equilibrio entre el cuerpo y el alma para juzgar cuando hay que temer y cuando no al defender la polis ${ }^{21}$.

Finalmente, el alma concupiscible da lugar a los artesanos. Este tipo de alma es la que se encuentra mayoritariamente en el hombre. Para evitar que los deseos gobiernen al hombre en su totalidad, es necesario obtener la virtud de la templanza, que consiste en vigilar no estar repletos de placeres corporales al superponer lo racional frente a lo concupiscible.

En términos de Filosofía Práctica, es necesario armonizar las tres partes mediante la medicina, la gimnasia, la música y la dialéctica ${ }^{22}$, retomaremos esta referencia en el apartado de consideraciones de la consejería filosófica; mientras tanto es necesario completar el concepto de alma en Platón para saber cómo se aplica la problematización.

En el Fedón, Platón expresa:

El alma es lo más semejante a lo divino, inmortal, inteligible y que está siempre idéntico consigo mismo, mientras que, a su vez, el cuerpo es lo más semejante a lo humano, mortal, multiforme, irracional, soluble y que nunca está idéntico a sí mismo $^{23}$

Esta cita significa dos cosas, en general. La primera, es una reminiscencia de la consideración hesiódica de la constitución humana, producto de elementos

\footnotetext{
${ }^{21}$ Esto se consigue cuidándolos con gimnasia y música, puesto que son cualidades que requieren este tipo de personas para cumplir su función.

${ }^{22}$ Cfr. PlATÓN: Diálogos. Tomo VI: Filebo, Timeo y Critias, Editorial Gredos, Madrid, 1992, p. 192.

${ }^{23}$ PLATÓN: Diálogos. Tomo III: Fedón, Banquete y Fedro, Editorial Gredos, Madrid, 1986, p. 71.
} 
divinos y titánicos ${ }^{24}$. No somos dioses, pero tampoco somos iguales a la restante materia; sino la fusión de ambos ámbitos. Platón la actualiza diciendo que el alma es la parte que prima y se asemeja a lo divino, mientras que el cuerpo al cambiar está sujeto a corromperse.

En segundo lugar, que el alma es inmóvil, en contraposición con el cuerpo, indica la actividad epistemológicamente intencional que el alma representa. Aristóteles también reconoce este papel del alma: "el alma conoce... en cuanto que es lo primero y de él se derivan las demás cosas" 25 .

Para Platón, el alma es inmóvil porque para conocer a un objeto necesita que este no se mueva, ya que el alma sigue el principio de que lo semejante tiene a lo semejante. Así, para conocer los objetos que son estables en sí mismos, el pensamiento debe ser estable y así conocerlo por semejanza. El presupuesto del que parte esta consideración no es otro que el de Parménides, a saber, conocemos algo que es (ón) porque es permanente, ya que al cambiar no es (mè ón) y "¿cómo se podría conocer lo que no es?"26.

La visión de Fedón, pues, muestra el alma como principio de inmovilidad por razones ontológicas. Son los paradigmas estables (Ideas) los que sólo pueden ser conocidos si el intelecto se vuelve estático, para igualar las naturalezas y conocer lo semejante por lo semejante. Para lograr esa koinonia ${ }^{27}$ es necesaria la contemplación. Entendida como "una mirada penetrante" ${ }^{28}$ que supone el principio de la actividad cognitiva tal como manda Platón (1986a, 117): "medita... lo que quiero mostrarte"29.

Por el contrario, en el Fedro considera al alma como un principio activo. Esto significa que el ateniense argumente múltiples puntos para alcanzar la verdad del alma. Según esta visión, Platón continúa defendiendo que el alma pertenece a la parte imperecedera, pero esta vez contrapone la posición de que si se está quieta, como en el Fedón, no podrá acercarse a sus objetos. Porque sólo hay dos tipos de naturalezas con respecto a lo que se mueve: aquello que es movido por otro y aquello que es movido por sí mismo ${ }^{30}$. Puesto que el alma tiene un movimiento intencional para poder conocer los objetos, entonces es movido por sí mismo. Si se mueve a si misma entonces no puede perder su ser, por lo que es inmortal. Así pues, como "es lo mejor que tenemos", prima sobre el

\footnotetext{
${ }^{24}$ Cfr. HESÍODO: Obras y fragmentos, Editorial Gredos, Madrid, 1978.

${ }^{25}$ ARISTÓTELES: Acerca del alma, Editorial Gredos, Madrid, 1978, pp. 141-142.

${ }^{26}$ PLATÓN: Diálogos. Tomo IV: República, Editorial Gredos, Madrid, 1986, p. 288.

${ }^{27}$ La comunión entre el alma y los objetos de la dialéctica.

${ }^{28}$ PLATÓN: Diálogos. Tomo IV: República, Editorial Gredos, Madrid, 1986, p. 120.

${ }^{29}$ PLATÓN: Diálogos. Tomo III: Fedón, Banquete y Fedro, Editorial Gredos, Madrid, 1986, p. 117.

${ }^{30}$ Cfr. PLATÓn: Diálogos. Tomo III: Fedón, Banquete y Fedro, Editorial Gredos, Madrid, 1986, p. 344.
} 
cuerpo, lo que la hace principio ingénito además de imperecedero. En consecuencia, al ser ingenerada el alma se mueve a sí misma y siempre se mueve.

Ahora bien, se mueve porque requiere alcanzar los arquetipos llamados Ideas. De esta necesidad Platón deriva cómo es que la realidad más divina que tiene el hombre, el alma, ha "caído" del mundo de las ideas y ha venido a este corrupto y mortal. Así, de acuerdo con un pasaje del Fedro: "Si [el alma] es perfecta y alada, surca las alturas, y gobierna todo el Cosmos. Pero la que ha perdido sus alas va a la deriva, hasta que se agarra a algo sólido, donde se asienta y se hace con un cuerpo terrestre" ${ }^{31}$.

Con esta cita, Platón quiere denotar un ascenso al conocimiento (muy semejante a la apertura hacia la luz del prisionero en el pasaje de la caverna). Este ascenso requiere un despliegue de alas que sólo ocurre cuando el alma es moralmente buena producto de entrenarse en la dialéctica ${ }^{32}$. Estas alas, de las que Platón habla en el Fedro, tienen su cumplimiento en el mito del auriga: "un conductor de caballos de los cuales uno es bueno y hermoso, y está hecho de esos mismos elementos, y el otro de todo lo contrario, como también de su origen" ${ }^{33}$. Así pues, encontramos este juego dialéctico entre un impulso que trae comportamientos buenos y otro que aporta destructivos. La lección es muy clara: el problema no radica en que uno corre desembocado, mientras el otro es más tranquilo, sino que hay que lograr una armonía entre ambos elementos. Esta tarea "resultará difícil y duro su manejo" "34; la forma de lograrlo es la phronesis, elemento en el que nos detendremos enseguida. Antes, empero, es necesario dar un cierre a la idea de movilidad del alma.

La movilidad que queda representada por esos jaloneos de los caballos, según el mito del auriga, no se entiende en términos del estagirita. Aristóteles sostiene que "no hay movimiento fuera de las cosas, pues lo que cambia siempre cambia $o$ sustancialmente $o$ cuantitativamente $o$ cualitativamente $o$ localmente" ${ }^{35}$. Pues él no concibe movimientos del alma sin cuerpo (al hablar del alma, dice: "cuerpo desde luego, no es, pero sí, algo del cuerpo, y de ahí que se

\footnotetext{
${ }^{31}$ PLATÓN: Diálogos. Tomo III: Fedón, Banquete y Fedro, Editorial Gredos, Madrid, 1986, pp. 345-346.

32 Porque la pauta socrática "el hombre hace mal por ignorancia" que en Platón hace eco, resuena al expresar también que para actuar moralmente hay que reconocer el bien, para actuar en consecuencia. Cuando el alma se libera de la ignorancia no sólo lo hace epistemológicamente, sino en el ámbito ético al disponer al hombre a vivir bien.

${ }^{33}$ PLATÓN: Diálogos. Tomo III: Fedón, Banquete y Fedro, Editorial Gredos, Madrid, 1986, p. 345.

${ }^{34}$ PLATÓN: Diálogos. Tomo IV: República, Editorial Gredos, Madrid, 1986, p. 345.

${ }^{35}$ ARISTÓTELES: Física, Editorial Gredos, Madrid, 1995, p. 80.
} 
dé en un cuerpo, y más precisamente en un determinado tipo de cuerpo"36), y en general cualquier movimiento si no es afectado por el tiempo y el espacio.

La concepción de movimiento difiere entre Aristóteles y Platón parcialmente. Mientras para el primero es "la actualidad de lo potencial en cuanto tal" ${ }^{37}$, y por esto se entiende el carácter dinámico del movimiento por el que no es cualquier actualidad, sino sólo la activa. Para Platón constituye un despliegue dialéctico del alma con una carga intencional, esto es, de acercamiento a los objetos de conocimiento.

Esto es, al sostener Aristóteles esta posición del movimiento en cuanto capacidad operativa se comprende que haya un tipo de cambio para cada categoría ontológica: para la de substancia la generación y la corrupción; para la cantidad, el aumento y la disminución; en cuanto al lugar, translación; y para la de cualidad, alteración. Lo que tienen en común todos esos cambios, y en virtud de lo cual les llamamos movimientos es la actualización procesual que experimentan. Por ejemplo, una casa está en movimiento mientras está siendo construida, cuando deja de serlo no se mueve en tanto cantidad. Lo que sí puede ocurrir es que se actualice en tanto cualidad, por ejemplo que se haga vieja, o que alguien la pinte.

De esta consideración, se deriva un comportamiento con respecto al sujeto y objeto de movimiento. Para Aristóteles, "todo moviente también es movido... Porque actuar sobre lo movible en cuanto tal es precisamente moverlo; pero el moviente hace esto por contacto de tal manera que al mismo tiempo experimenta también una modificación" ${ }^{, 38}$.

Aquí es donde Aristóteles non sequitur por Platón. Para éste el alma sí se mueve, pero también tiene presentes elementos permanentes; porque en tanto conoce subsiste "algo" que permanece igual en el alma, a saber, esa identidad con el ser. Los objetos permanecen idénticos en cuanto que tienen el mismo ser, aunque no la misma forma de ser, que ya ha sido aprendida por el sujeto cognoscente. Ocurre así porque no conocemos por el contacto del alma con los objetos, sino que el intelecto media entre los sentidos que comprenden lo físico y lo inteligible, o en otras palabras, el intelecto mismo es el que contempla las ideas.

Cabe la aclaración de que al establecer la existencia del intelecto no estamos creando una hipóstasis (no lo hacemos substancia), pues este es una facultad. Si se entiende esto, entonces el esquema que se sigue es el de sustancia-facultadsustancia, según la comprensión del periodo.

\footnotetext{
${ }^{36}$ ARISTÓTELES: Acerca del alma, Editorial Gredos, Madrid, 1978, p. 174.

${ }^{37}$ ARISTÓTELES: Física, Editorial Gredos, Madrid, 1995, p. 80.

${ }^{38}$ ARISTÓTELES: Física, Editorial Gredos, Madrid, 1995, p. 84.
} 
Platón, pues, se diferencia de esta manera de la concepción de movimiento del estagirita, porque el ateniense plantea una síntesis de opuestos óntica y lógicamente a través de la dialéctica. Esto le valdrá una severa crítica por parte de Aristóteles diciéndole que su posición dialéctica no aclara las cosas "cuando dice... que el movimiento es alteridad, desigualdad, no ser" ${ }^{39}$. Sin embargo, la síntesis dialéctica supera los planteamientos de Aristóteles en tanto que no supone una transformación substancial, cuantitativa, y sobretodo locativa: puntos de crítica de la visión platónica sobre el alma a través del De anima aristotélico. En esos pasajes, el estagirita sostiene que el alma platónica no puede ser una sustancia porque ella supondría un movimiento locativo, y todo movimiento supone un espacio y tiempo. ¿Así pues, hacía qué parte del cuerpo se movería el alma?

La dialéctica se da porque sí hay un movimiento en tanto cualidad (es decir, está en concordancia con la teoría general del movimiento expuesta en Física); este cambio es intencional, esto es, una modificación actitudinal. Aunque no es como Aristóteles plantea, de contacto directo, pues por contemplación de los conceptos se está libre de la ignorancia, listo para vivir virtuosamente. Este último es el punto clave de la therapeia griega, pero para comprenderla suficientemente es necesario todavía aclarar el concepto de phronesis, porque hay una semejanza conceptual entre ambas. Mientras la phronesis es una virtud del alma, la therapeia es la actividad que provee de soporte a la phronesis. Pues al suponer la contemplación como una intentio, ella no conoce las ideas, sino que las intuye, i.e., el intelecto es el que las evidencia. La facultad del intelecto se contacta con el yo que soporta las actividades, y que designamos como psique. El esquema entonces es el siguiente: psique (sujeto), intelecto (facultad), Ideas (objeto); no hay contacto directo como en la observación requerida por Aristóteles.

Con lo dicho, cabe concluir de la concepción del alma en Platón es una entidad distinta a la planteada por Havelock ${ }^{40}$, a saber, que el alma está relacionada con los procesos activo-pasivos del conocimiento. El alma es más que la superación de opuestos entre lo activo y lo pasivo, sino la síntesis entre lo estable y lo mutable. Con toda justificación aquí aplicarían las palabras del Parménides (hay que hacer que, de alguna manera, lo que no sea, sea; y lo que sea, no $\mathrm{sea}^{41}$ ) pues las consecuencias diferentes de que el alma sea idéntica a sí misma cuando conoce y cambiante para obtener los objetos muestra dos

\footnotetext{
${ }^{39}$ ARISTÓTELES: Física, Editorial Gredos, Madrid, 1995, p. 83.

${ }^{40}$ Cfr. HAVELOCK, E.: Preface of Plato, University Press, London, 1963, p. 216.

${ }^{41}$ Cfr. PlATÓN: Diálogos. Tomo V: Pármenides, Teeteto, Sofista, Político. Editorial Gredos, Madrid, 1998, p. 126.
} 
momentos discursivos de un solo concepto. Porque al ser estable requiere del movimiento para alcanzar eidéticamente sus objetos, pero si siempre estuviera cambiante no podría obtener su esencia (lo que es permanente).

$\mathrm{Y}$ al entender que ambos principios coexisten se genera una visión compleja del concepto. Carlos García Gual lo resume de la siguiente manera: "El alma es lo racional y espiritual en el hombre, su auténtico yo, frente al cuerpo, instrumento y receptorio de lo sensible" ${ }^{\prime 2}$. Esto vale con la advertencia que, al hablar del alma como un "yo", no se entiende como una entidad independiente del cuerpo, sino como la excelencia ${ }^{43}$ que permite que el cuerpo se mueva y permanezca idéntico hasta que se corrompa físicamente.

\section{Sobre el concepto de phronesis: o cómo se usan los argumentos}

El concepto de phronesis juega un papel importante en la aplicación de la filosofía platónica para la consejería. Para comenzar, debemos aclarar que la noción difiere entre Aristóteles y Platón; para el primero denota un elemento de la racionalidad práctica pues se manifiesta como una virtud que traducimos con el signo de prudencia; para el segundo expresa una disposición matemática con la implicación moral de llevar una buena vida, su traducción más exacta es discernimiento.

El estagirita entiende por virtud aquel hábito producto de la constante práctica de un acto bueno, y en consecuencia phronesis significa "ser capaz de deliberar rectamente sobre lo que es bueno y conveniente para sí mismo... para vivir bien" 44 . En particular, la virtud de la prudencia se consolida con un modo de ser racional verdadero y práctico porque siempre orienta al hombre hacia el bien. Y por lo tanto, no está restricto ni al ámbito universal ni a la teorización. La prudencia es una virtud dianoética ${ }^{45}$ que es profundamente práctica y que se relaciona con los particulares.

En el ateniense, en cambio, abarca a la inteligencia en general; phronesis en Platón significa "[c]onocimiento exacto, teórico y práctico a la vez; cuyo objeto no es otro que la contemplación del Bien" 46 .

\footnotetext{
${ }^{42}$ PLATÓN: Diálogos. Tomo III: Fedón, Banquete y Fedro, Editorial Gredos, Madrid, 1986, p. 40.

${ }^{43}$ Aquí no como areté, sino como el más alto grado de ser.

${ }^{44}$ ARISTÓTELES: Ética a Nicómaco. Ética Eudemia, Editorial Gredos, Madrid, 1985, p. 275.

${ }^{45}$ Aristóteles distingue dos tipos de virtudes en el libro I de Ética a Nicómaco: las dianoéticas y las éticas. Las primeras se caracterizan por relacionarse con la inteligencia, dentro de este grupo se incluyen la sabiduría y la prudencia. Mientras que las segundas, por la práctica; siendo ejemplos la liberalidad y la moderación.

${ }^{46}$ ARISTÓTELES: Acerca del alma, Editorial Gredos, Madrid, 1978, pp. 63-64.
} 
Este conocimiento en términos platónicos está profundamente ligado a la inconmensurabilidad de la realidad porque phronesis es el resultado de problematizar. Al hacer perplejo a un yo, el sujeto toma una actitud moral de discernimiento con respecto a los problemas; sabe que no pueden ser solucionados completamente (aporein), pero siempre lleva una disposición mental para solucionarlos (phronein). Esta disposición tiene una carga conceptual próxima a decisión, intención, estado de la mente o propósito; a través del cual se puede aplicar al pensamiento político o ético ${ }^{47}$.

Esta virtud (phronesis) se identifica en Platón con una disposición de tipo matemática porque el discernimiento permite realizar una valoración de las situaciones y tomar una decisión al respecto. Para desarrollarla, Platón cree que se debe seguir un programa extenso de ciencias entre las que incluye la aritmética, la geometría plana, la estereometría, la astronomía, la armonía, para finalmente poder acceder al estudio supremo, la dialéctica ${ }^{48}$. Con estas referencias propedéuticas el guardián del Estado (el filósofo) podría gobernar correctamente, y vivirían de acuerdo a la idea del Bien.

$\mathrm{Al}$ discernir el yo mide los pros y los contras de las situaciones sacándole a los bienes la utilidad que sólo se obtiene al usarlos bien, porque dice el estagirita que lo que es útil puede ser usado bien o $\mathrm{mal}^{49}$. Platón también sostiene que es feliz quien use el discernimiento en cada una de las situaciones; el contexto en el que lo expresa es el de identificar la virtud con el discernimiento porque la virtud es un bien que debe usarse correctamente, y en eso consiste el discernimiento, al igual que otras excelencias (areté):

Por ejemplo, el valor: si no fuera discernimiento el valor, sino una suerte de temeridad, ¿no es cierto que cuando un hombre es temerario y carece de juicio, recibe daño, mientras que saca su provecho, en cambio cuando tiene juicio?... [Será útil si resulta hecho con juicio; sin juicio, dañino porque] Todo lo que el alma emprende y lo que persevera, cuando el discernimiento lo guía, acaba con felicidad; si lo hace con el no-discernimiento, acaba en lo contrario $^{50}$.

Phronesis en Platón significa una competencia matemática que se iguala al discernimiento porque puede realizar cálculos de las razones, estableciendo cuáles son más plausibles que otras en tanto más o menos. Para realizarlos

\footnotetext{
${ }^{47}$ Cfr. HAVELOCK, E.: Preface of Plato, University Press, London, 1963, p. 213.

${ }^{48}$ Cfr. PLATÓN: Diálogos. Tomo IV: República, Editorial Gredos, Madrid, 1986.

${ }^{49}$ Cfr. ARISTÓTELES: Ética a Nicómaco. Ética Eudemia, Editorial Gredos, Madrid, 1985, p. 211.

${ }^{50}$ PLATÓN: Diálogos. Tomo II: Gorgias, Menéxeno, Eutidemo, Menón y Crátilo, Editorial Gredos, Madrid, 1983, p. 317.
} 
requiere que el yo tenga una actividad dialéctica y el movimiento generado se conecte con la actividad teorético-práctica. Al ocurrir esto, el cálculo que hace la mente es doble: con respecto a la realidad y con respecto a los argumentos para elegir una línea de acción que modifique esa realidad.

Con respecto a la realidad genera un estado de la cuestión, tanto en lo epistémico como en lo ontológico. Sólo puede lograr esto ordenando en grados de conocimiento y de ventajas o desventajas que posee en el momento la situación.

Con respecto a los argumentos, además de revisar teóricamente que sean razonables, debe pesar ${ }^{51}$ los beneficios de hacer de tal o cual cosa y luego actuar en consecuencia. Esta es una de las razones por la que phronesis es un beneficio de la filosofía, a saber, que provee de un cálculo para vivir bien; porque no se argumenta un discurso para vivir una cosa distinta, sino para poner en práctica la mejor propuesta que ha sido pesada, pues "si hemos de ser felices, debemos marchar por el camino que trazan los pasos de esos argumentos" $" 52$.

Siguiendo las palabras del ateniense, la consejería filosófica busca que el interlocutor aplique correctamente el discernimiento para obtener su felicidad. La eudaimonia es un beneficio al que muchos seres humanos aspiran buscándolo en el dinero, el placer, una realidad más allá de este mundo o un estado de la conciencia. Sea de cualquier manera no es algo que sea despreciado, y aunque no es fácil adquirirla, según Platón, porque es producto de ejercitarse en la virtud, sí establece de manera clara cómo obtenerla: De los bienes hay que escoger los de mayores tamaños y evitar los más pequeños; mientras que de los males, lo contrario ${ }^{53}$.

Con esto quiere decir que si pesamos lo agradable frente a lo agradable, la elección será sobre el que aporte placer en mayor cantidad. Pero si es entre dolores, entonces hay que escoger los menos, y en menor cantidad también. Ahora si pesamos lo agradable frente a lo doloroso, será mejor elegir aquello en lo que la parte penosa sea superada por la placentera, la que cumpla estos requisitos tanto en lo próximo como en lo distante es la que más beneficios trae. Finalmente, si los placeres son superados por las penas, hay que abstenerse de materializar la elección porque trae más perjuicios que beneficios.

\footnotetext{
${ }^{51}$ Platón usa la palabra pesar como una metáfora para expresar lo plausible que son los argumentos. He preferido mantener su uso porque representa, en el campo de la lógica, una relación matemática de más y menos como ocurre con los objetos.

${ }^{52}$ PLATÓN: Diálogos. Tomo IV: República, Editorial Gredos, Madrid, 1986, p. 116.

${ }^{53}$ Cfr. PlAtón: Diálogos. Tomo I: Apología, Critón, Eutifrón, Ion, Lisis, Cármides, Hipias menor, Hipias mayor, Laques, Protágoras, Editorial Gredos, Madrid, 1981, p. 580.
} 
¿Cómo, pues, podemos obtener la felicidad a través de la phronesis? La forma en que actúa el discernimiento es precisamente sobre un sujeto, porque phronesis es la materialización del cuidado del alma. En tal caso, hay que comprender que la demencia es una de las enfermedades del alma que se manifiesta en dos clases:

La locura y la ignorancia. Por tanto, debemos llamar enfermedad a todo lo que produce uno de estos dos estados cuando alguien lo sufre y hay que suponer que para el alma los placeres y dolores excesivos son las enfermedades mayores. Pues cuando un hombre goza en exceso o sufre lo contrario por dolor, al esforzarse fuera de toda oportunidad por atrapar el uno y huir del otro, no puede ni ver ni escuchar nada correcto, sino que enloquece, absolutamente incapaz de participar de la razón en ese momento ${ }^{54}$

Esta demencia, que se configura como una de las peores enfermedades del alma bajo la forma de locura y de la ignorancia, es precisamente lo contrario a la felicidad, pues ocurre cuando el cálculo de los placeres y dolores no se realiza correctamente y se presentan de manera excesiva. El tratamiento más efectivo no es otro que ejercitarse en la vida virtuosa del discernimiento para sanar el alma.

Con esta cita, Platón también nos recuerda que las enfermedades del alma son peores que las del cuerpo; y aun cuando en el Fedón ha dicho que el cuerpo es un principio limitante frente al alma ${ }^{55}$ consolidándose con un menor estatus ontológico (de esta primacía que tiene el alma sobre el cuerpo es que las enfermedades del alma son peores que las de su opuesto), hay que tratar ambas porque unas pueden ocasionar otras y viceversa; por lo que al plantearse la therapeia del alma se hace referencia a buscar la salud integral del ser humano.

Las enfermedades del cuerpo pueden ocasionar las del alma, así lo dice Platón: "Como su alma es insensata y está enferma a causa de su cuerpo, parece malo, no como si estuviera enfermo, sino como si lo fuera voluntariamente" ${ }^{96}$. También en lo que concierne a los dolores, el alma recibe de la misma manera mucho daño a causa del cuerpo, porque:

Si las llamas ácidas y saladas... o sus humores amargos y biliosos vagan por el cuerpo sin encontrar salida al exterior, ruedan de un lado a otro dentro y

\footnotetext{
${ }^{54}$ PLATÓN: Diálogos. Tomo VI: Filebo, Timeo y Critias, Editorial Gredos, Madrid, 1992, p. 252.

${ }^{55}$ Cfr. PLATÓN: Diálogos. Tomo III: Fedón, Banquete y Fedro, Editorial Gredos, Madrid, 1986, p. 71.

${ }^{56}$ PLATÓn: Diálogos. Tomo VI: Filebo, Timeo y Critias, Editorial Gredos, Madrid, 1992, p. 253.
} 
mezclan el vapor que expiden con la revolución del alma, de modo que dan lugar a múltiples enfermedades -en mayor o menor número, de menor o mayor importancia-, al trasladarse a los tres asientos de aquélla [la racional, la irascible y la concupiscible $]^{57}$.

Así, el alma repercute en el cuerpo y este en aquella de manera coordinada; aunque con diferencia de grado porque los males del alma repercuten más en el cuerpo por su estatus ontológico, y en consecuencia se puede curar al cuerpo también desde el alma ${ }^{58}$.

La forma de cuidar el cuerpo mediante el alma es a través del conocimiento, pues recuérdese que al Platón seguir la máxima socrática que nadie es malo voluntariamente, sino por ignorancia, entonces la virtud, y en particular el discernimiento, constituyen una verdadera liberación de la maldad y la infelicidad. Porque el malo se hace tal por un "mal estado del cuerpo o por una educación inadecuada",59, sea que esté afectado su cuerpo o su alma respectivamente.

Cuando un cuerpo tiene miembros demasiado largos o cortos, pero una mente lúcida, proyecta una imagen grotesca por la mala distribución corporal y la falta de armonía entre sus contrarios, además puede recibir golpes, torceduras o producirse muchos males a sí mismo. Aquí el tratamiento es armonizar primero el alma mediante la música y la gimnasia, para que pueda intervenir eficientemente la medicina porque "es por medio del alma que curan al cuerpo, y el alma no puede curar nada si está enferma o se enferma"60.

De la misma manera ocurre cuando en un cuerpo grande y altivo tiene una capacidad intelectual débil e inferior, puesto que si existen dos tipos de deseos en los hombres (los del cuerpo como la alimentación, y los del alma, como el conocimiento), los movimientos de la parte más desarrollada se impondrán haciendo al alma olvidadiza y con serias dificultades para el aprendizaje. Aquí el tratamiento es liberar al sujeto de su ignorancia, sacarlo de la caverna en la que se encuentra. Para hacer que reaccione es necesario problematizarlo, porque al poner de manifiesto las aporías que existen en sus planteamientos debe renunciar a su posición de soberbia. Sólo hasta entonces puede estar dispuesto a investigar para llegar a la verdad y retirarse de la ignorancia.

\footnotetext{
${ }^{57}$ PLATÓN: Diálogos. Tomo VI: Filebo, Timeo y Critias, Editorial Gredos, Madrid, 1992, p. 253.

${ }^{58}$ Cfr. PLATÓN: Diálogos. Tomo IV: República, Editorial Gredos, Madrid, 1986, p. 179.

${ }^{59}$ PLATÓN: Diálogos. Tomo VI: Filebo, Timeo y Critias, Editorial Gredos, Madrid, 1992, p. 253.

${ }^{60}$ PLATÓN: Diálogos. Tomo IV: República, Editorial Gredos, Madrid, 1986, p. 187.
} 


\section{Algunos comentarios para la consejería filosófica}

En primer lugar, es necesario ser consciente de que el cuidado de sí invita a su complemento a través de otras disciplinas (Platón piensa en la música, la gimnasia y la medicina) para obtener un cuidado integral del interlocutor con el que tenemos contacto.

Estos campos ayudan a equilibrar el cuerpo y el alma para que la filosofía también haga su parte. Al tener la disposición para dialogar las situaciones, una recomendación importante para el filósofo es que no busque decirle al sujeto lo que debe hacer, sino ayúdale dialécticamente (a través de preguntas) para que encuentre las soluciones por su cuenta. Para lograrlo, es necesario partir de lo que el interlocutor cree y guiarlo para que se dé cuenta de las falacias que comete en sus planteamientos. El camino es problematizarlo, es decir, contraponer sus proposiciones con otras para obtener argumentos más sólidos y consistentes.

La discusión se extenderá en tanto no se obtengan planteamientos que le ayuden al sujeto a pasar al siguiente nivel, sin olvidar, por supuesto que el interlocutor también tiene otras tareas cotidianas y que será necesario hacer cortes parciales; aun con esto, las sesiones generalmente son de duración breve porque la finalidad es adelantar en términos de la disposición del sujeto y la habilidad del filósofo.

Sólo cuando el interlocutor reconozca su ignorancia y esté dispuesto a investigar conjuntamente con el filósofo es cuando pueden develarse los argumentos para vivir mejor y ponerlos en práctica implicaría ser feliz. Cuando ya se tiene ese conocimiento reconocer las mejores alternativas de actuación es necesario mantenerse en disposición de diálogo para problematizarse y problematizar. Es compromiso ahora del sujeto participante para actuar en consecuencia, a sabiendas que las razones por las cuales actúa son las mejores y sus resultados los más felices posibles.

En segundo lugar, decir que, en términos platónicos, la consejería supone como resultado la felicidad no garantiza que el camino para obtenerla sea algo sencillo. Lo que es importante resaltar aquí, como otras técnicas de la Filosofía Aplicada, es que no se limita a ningún tipo de personas, siempre y cuando tengan la disposición de participar en ellas. Esto es muy importante porque el discernimiento que se ha argumentado puede avalar la participación tanto de otros filósofos, guardianes y artesanos (recordando las características del alma que se mencionaron brevemente).

No ahondé en la descripción de cada una de las clases de la polis porque su distinción implica un trabajo más histórico-filosófico en vez de práctico como aquí se pretende. En cambio, se puede argumentar que la consejería 
puede aplicarse a casi todos los problemas que incluyan disposición por parte del sujeto a dialogar ${ }^{61}$. Y por lo tanto, no se restringe a solucionar problemas emocionales o sociales, sino también de índole personal, y con esto quiero decir, que el discernimiento que se logra en el sujeto, debido a practicar con el filósofo el cálculo más exacto de la realidad hace que tanto el filósofo, el guardián y el artesano pueda desenvolverse mejor y sus habilidades prácticas también mejoren en tanto que excelencias (areté).

Por extensión del proceso, no se crea una dependencia entre el interlocutor y el terapeuta porque el sujeto participante desarrolla un método para discernir sobre los argumentos. Ante todo, el filósofo es el especialista y de él depende que los procesos de problematización y obtención de la tranquilidad del sujeto al reconocer lo que puede hacer en sus circunstancias sean exitosos en tanto que el interlocutor coopere. Si el sujeto aprende bien la forma de guiar su vida entonces estará desarrollando paulatinamente su discernimiento (phronesis) en los términos expresos, aunque eso no signifique que si requiere otra intervención filosófica pueda hacerla en vistas a fortalecer su capacidad de problematizarse y pesar las razones. El filósofo tiene el compromiso moral de apoyarlo para disipar otro tipo de falacias que entorpezcan su crecimiento, sabiendo que es un profesional y que su soporte es en vías que se vuelva un sujeto autónomo del terapeuta.

En tercer lugar, argumentar que el cuidado de sí (epimeleia heautou) implica sobre todo cuidar del alma porque tiene primacía ontológica en tanto que conoce los objetos por semejanza estáticamente con el ser y de manera dinámica con la intentio. Luego, se puede cuidar el cuerpo a través del alma; sin embargo, no se debe descartar que el cuidado de sí implica tratarse medicamente porque las enfermedades del cuerpo también pueden afectar al alma. En cualquier caso, es importante remarcar que la consejería filosófica, al buscar un equilibrio integral del paciente, invitaría al interlocutor a tratase a través de la música, la gimnasia, la medicina y la filosofía en su conjunto.

Finalmente ${ }^{62}$, es importante no pasar por alto que el cuidado de sí implica ver al sujeto como el "punto hacia el cual se orienta la actividad reflexiva, esa actividad meditada que vuelve del individuo al individuo mismo"63.

\footnotetext{
${ }^{61}$ Con la debida distinción que la consejería filosófica no es una psicoterapia y que en tanto no incluya un tratamiento psicológico o psiquiátrico, puede intervenir eficazmente cuando el terapeuta esté debidamente calificado.

${ }^{62}$ No es necesario profundizar más sobre la técnica en este apartado, las referencias que se han hecho sólo son recomendaciones que se derivan de los tres primeros apartados. Ellos son el fundamento teórico y las guías para la práctica de la consejería a partir del platonismo.

${ }^{63}$ PIAZZE, J.: "El cuidado de sí. La inversión del platonismo desde la mirada de Michel Foucault", disponible on-line en: http://www.biopolitica.cl/docs/piazze_cuidado_final[1].pdf (último acceso 23
} 


\section{Bibliografía}

ARISTÓTELES: Acerca del alma, Editorial Gredos, Madrid, 1978

ARISTÓTELES: Ética a Nicómaco. Ética Eudemia, Editorial Gredos, Madrid, 1985.

ARISTÓTELES: Física, Editorial Gredos, Madrid, 1995.

FOUCAULT, Michel: Historia de la sexualidad. Tomo II: El uso de los placeres, Editorial Siglo Veintiuno, México, 1998.

- Tecnologías del yo y otros textos afines. Editorial Paidós, Barcelona, 1900.

HAVELOCK, E.: Preface of Plato, University Press, London, 1963.

HESÍODO: Obras y fragmentos, Editorial Gredos, Madrid, 1978.

PIAZZE, J.: "El cuidado de sí. La inversión del platonismo desde la mirada de

Michel Foucault", disponible on-line en: http://www.biopolitica.cl/docs/ piazze_cuidado_final[1].pdf (último acceso 23 de marzo de 2012)

PLATÓN: Diálogos. Tomo I: Apología, Critón, Eutifrón, Ion, Lisis, Cármides, Hipias menor, Hipias mayor, Laques, Protágoras, Editorial Gredos, Madrid, 1981.

PLATÓN: Diálogos. Tomo II: Gorgias, Menéxeno, Eutidemo, Menón y Crátilo, Editorial Gredos, Madrid, 1983.

- Diálogos. Tomo III: Fedón, Banquete y Fedro, Editorial Gredos, Madrid, 1986.

- Diálogos. Tomo IV: República, Editorial Gredos, Madrid, 1986.

- Diálogos. Tomo V: Pármenides, Teeteto, Sofista, Político. Editorial Gredos, Madrid, 1998.

- Diálogos. Tomo VI: Filebo, Timeo y Critias, Editorial Gredos, Madrid, 1992.

- Diálogos. Tomo VIII: Leyes, Editorial Gredos, Madrid, 1999.

REALE, G.: Raíces culturales y espirituales de Europa: por un renacimiento del hombre europeo. Editorial Herder, Barcelona, 2005.

SCOTT, D.: Plato's Meno, Cambridge University Press, Cambridge, 2005.

VELÁSQUEZ, O.: "La República de Platón: Línea, Caverna, Dialéctica", disponible on-line en: http://www.diadokhe.cl/media/platonica/ republica_polit.pdf (último acceso 19 de abril de 2011). 